\title{
Fighting the odds to make it even: Mapping an affordance ecosystem in a kindergarten community
}

\author{
Jeanette Clarkin-Phillips
}

\begin{abstract}
This thesis is a case study of a kindergarten in one of the most deprived areas of Aotearoa New Zealand. Through the documentation of the stories of management, teachers and families, the thesis explores how the transformation of the kindergarten and a policy intervention have provided multiple opportunities and affordances for adults to realise their aspirations. Bourdieu's logic of practice thinking tools and Bronfenbrenner's ecological systems theory are intertwined to theorise about the contribution of macrosystem ideologies that position communities as vulnerable and frame up subsequent exosystem policy attempts to intervene.
\end{abstract}

The concept of habitus is applied to explain how a commitment to social justice and an empowerment view of individuals and communities can afford conditions for the transformation of habitus. The thesis argues that the level of strength of an affordance is significant in the recognition and utilisation of opportunities and that early childhood teachers can be mesosystem agents in mediating affordances. Inherent in the thesis is the acknowledgment that early childhood services have the potential to contribute to positive life trajectories for adults as well as children, particularly for those in communities who have the odds stacked against them.

The thesis adds to the scholarship about habitus and its transforming features and contributes to a deeper understanding about the role of effective early years services as powerful intervention sites for adults. The unique combination of Bourdieu and Bronfenbrenner's theories offers new insights about the individual/environment relationship and impacts on agency. The thesis outlines a range of policy implications for consideration with respect to communities who are poorly provided for due to dominant ideological discourses and reiterates the right of all individuals to realise their hopes and dreams. 